\title{
Magnitude of discordance between registry data and death certificate when evaluating leading causes of death in dialysis patients
}

Jean-Philippe Lafrance ${ }^{1,2,3^{*}}$, Elham Rahme ${ }^{4,5}$, Sameena lqbal ${ }^{4,6}$, Martine Leblanc ${ }^{2,3}$, Vincent Pichette ${ }^{1,2,3}$, Naoual Elftouh ${ }^{1}$ and Michel Vallée $e^{2,3}$

\begin{abstract}
Background: Discordance between dialysis registry and death certificate reported death has been demonstrated. Since cause of death is measured using registry data in dialysis patients and death certificate data in the general population, comparisons of cause of death proportions between dialysis patients and the general population may be biased. Our aim was to compare the proportion of deaths attributed to cardiovascular disease (CVD), malignancy, and infections between patients receiving dialysis and the general population using death certificates for both, and to quantify the magnitude of discrepancy between registry and death certificate estimates in dialysis patients.
\end{abstract}

Methods: A retrospective cohort study of 5858 patients initiating maintenance dialysis between 2001 and 2007 was conducted. Cause of death was obtained from both registry and death certificate data for dialysis patients, and from death certificate data for the general population.

Results: Compared to the general population, use of death certificate data in dialysis patients resulted in smaller differences in the proportion of deaths attributed to CVD or infection than that from the registry. In the general population, the proportion of deaths due to CVD is $29.3 \%$ for men and $28.2 \%$ for women, and the proportion of deaths due to infection is 3.3\% for men and 3.6\% for women. For men, the proportion of deaths in dialysis patients due to CVD using registry data is $41.5 \%$, compared with a proportion of $32.1 \%$ using death certificate data. Similarly for women, the proportion of deaths due to CVD using registry data is $35.2 \%$ and that using death certificate data $24.3 \%$. The proportion of deaths due to infection in dialysis patients follows the same pattern: for men, the proportion of deaths due to infection using registry data is $9.9 \%$ and that from death certificate data at 5.0\%; while for women the proportions are $11.6 \%$ and $4.8 \%$, respectively.

Conclusions: While absolute cause-specific mortality rates did differ, evaluation of causes of death using death certificate in dialysis patients in Quebec revealed that they do not have substantially different proportion of death due to CVD or infections than the general population. Infections appeared to be a frequent complication leading to death, suggesting that infections are an important target to consider for reducing mortality in dialysis populations.

Keywords: Registries, Renal dialysis, Kidney failure, Chronic, Mortality, Cardiovascular diseases, Infections

\footnotetext{
* Correspondence: jean-philippe.lafrance@umontreal.ca

${ }^{1}$ Centre de recherche Hôpital Maisonneuve-Rosemont, Montréal, Canada

²Département de Médecine, Université de Montréal, Montréal, Canada

Full list of author information is available at the end of the article
} 


\section{Background}

In Canada, more than 22000 patients were receiving chronic dialysis in 2009 , increasing by nearly $20 \%$ in five years [1]. Cardiovascular disease (CVD) is the leading cause of mortality among dialysis patients, followed by infections [1]. It is well-established that dialysis patients have a higher mortality rate than the general population (GP) [1-3], and some data suggest that they have a higher proportion of death due to CVD than the GP $[4,5]$.

Understanding causes of death in a given population is important, as this data may guide prevention efforts, patient management, and clinical or research resources allocation. Many countries, including Canada, rely on registry data to produce estimates of causes of death for their dialysis population. In the GP, death certificates are considered the best practical source of truth at a population level. Since cause of death is measured using registry data in dialysis patients and death certificates in the GP, comparisons of cause of death proportions between dialysis patients and the GP may be biased. Reports comparing death certificates with dialysis registry data have demonstrated poor cause of death concordance [6,7]. However, the quantification of the difference relative to GP estimates has not been undertaken. Using a single source of truth, such as death certificates, through linkage of databases may produce more reliable estimates and may drive better clinical, research and administrative decisions.

Interestingly, while many CVD-oriented interventions such as use of statins [8,9] or angiotensin converting enzyme inhibitors [10] have resulted in some improvement in outcomes (such as reduction in atherosclerotic events), none have been demonstrated to lower mortality in the dialysis population. While pathogenic processes for CVD are probably different in the dialysis population compared to the GP, the inability of large studies to demonstrate improved survival, may suggest that attention to CVD deaths alone is insufficient to reduce mortality. Attention to other important contributors, such as infections, may be important [3]. In order to inform decision-making more accurately concerning intervention targets, assessment of causes of death proportions among dialysis patients should be ascertained using the same source of truth as in the GP. Our aim was to compare the proportion of deaths attributed to CVD, malignancy, and infections between patients receiving dialysis and the GP using death certificates for both, and to quantify the magnitude of discrepancy between registry and death certificate estimates in dialysis patients.

\section{Methods}

\section{Data sources and study population}

Data were obtained from the national Canadian dialysis registry, the Canadian Organ Replacement Register (CORR), and the provincial health services administrative databases of the province of Québec, Canada. CORR provides descriptive statistics on dialysis incidence, prevalence and patients' characteristics, and its data have been used successfully in numerous scientific publications [11-15].

All Québec residents, more than 8 million inhabitants, are covered for their physician and hospital services by a universal single-payer health care system (Régie de l'assurance maladie du Québec - RAMQ). The RAMQ physician claim databases include all visits, diagnosis codes and procedures during in- or outpatient encounters. RAMQ also hosts the hospital discharge summary databases. The Institut de la statistique du Québec (ISQ) holds official governmental vital statistic databases, which include dates and causes of death as reported on the death certificate. Information on data sources is summarized in Table 1.

From CORR, RAMQ and ISQ, data were obtained for all patients initiating chronic dialysis (without a prior kidney transplant) between January 1st, 2001 and December 31st, 2007 in the province of Québec. Patients with less than 90 days of dialysis were excluded. The study cohort consisted of all patients who were present in both the CORR and RAMQ databases as incident dialysis patients. An incident cohort was used, since comorbidities and causes of death may highly depend on

Table 1 Data sources

\begin{tabular}{|c|c|c|c|}
\hline & $\begin{array}{c}\text { Canadian organ replacement } \\
\text { register (CORR) }\end{array}$ & $\begin{array}{c}\text { Institut de la statistique du } \\
\text { Québec (ISQ) }\end{array}$ & $\begin{array}{c}\text { Régie de l'assurance maladie du } \\
\text { Québec (RAMQ) }\end{array}$ \\
\hline Type & Dialysis registry & Provincial vital statistics & $\begin{array}{l}\text { Medical claims and hospital discharge } \\
\text { summaries database }\end{array}$ \\
\hline Population included & All chronic dialysis patients in Canada & $\begin{array}{l}\text { All residents in Québec } \\
\text { (general population) }\end{array}$ & $\begin{array}{l}\text { All residents in Québec } \\
\text { (general population) }\end{array}$ \\
\hline Filling of cause of death field & $\begin{array}{l}\text { Registered nurse responsible for the unit, } \\
\text { helped with treating physician }\end{array}$ & Treating physician & N/A \\
\hline Cause of death coding scheme & $\begin{array}{l}\text { Internal coding scheme (code entered } \\
\text { directly on the reporting form) }\end{array}$ & $\begin{array}{l}\text { ICD-10 by trained archivists } \\
\text { centrally }\end{array}$ & N/A \\
\hline
\end{tabular}

Abbreviations: ICD-10, International Classification of Diseases, 10th Revision. 
dialysis vintage. Patients were followed from day 90 after dialysis initiation until date of death or end of the study period.

Mortality rates in the GP of Québec were obtained from the ISQ website for the years 2001 to 2007 [16].

\section{Measurement of dates and causes of death}

CORR data provided a date of death (month and year) and a cause of death using an internal classification (78 elements). The cause of death is usually coded by the registered nurse responsible in each dialysis unit.

ISQ also provided a date of death (month and year) and a cause of death coded using the International Classification of Diseases, 10th Revision (ICD-10). Death certificates are filled by physicians and then coded by trained archivists at ISQ. For the evaluation of dates of death concordance, the date of death provided by RAMQ-ISQ was considered the source of truth.

The cause of death is mandatory on the death certificate (ISQ) and includes different fields: 1) underlying disease that eventually led to death; 2) diseases in the pathway to death ("secondary causes"); and 3) the disease or complication that directly led to death ("direct cause"). For example, a patient may have the following pathway: had an acute myocardial infarction (underlying cause), followed by a cardiogenic shock (secondary cause), and dies after a ventilator-associated pneumonia in the intensive care unit (direct cause).

Causes of death were classified in four mutually exclusive categories: CVD (ICD-10: I00-I99), infection (A00-B99, J10-J18), malignancy (C00-D48), and other. Among the "other" category, kidney failure (N17-N19) and diabetes (E10-E14) were identified using death certificate, but those categories had no code using CORR internal scheme.

\section{Statistical analysis}

Dates of death from CORR and ISQ were considered concordant if they occurred in the same month, or in a contiguous month. Concordance was measured using kappa statistics.

Mortality rates were calculated by dividing the number of deaths by the total patient-years of follow-up. 95\% confidence intervals (CI) for rates were calculated using a Poisson distribution. Mortality rates for the GP were indirectly standardized using the study cohort age and sex structure. Cumulative survival function was calculated using Kaplan-Meier method.

Causes of death were considered concordant if they fell within the same category. Two concordance analyses were done for causes of death: 1) CORR versus ISQ underlying cause and 2) CORR versus ISQ direct cause. Concordance was measured by non-weighted kappa statistics for categorical variables [17], and by a Chisquare test for proportions.

\section{Sensitivity analyses}

Some codes in CORR classification system are broad and may include various categories: Cardiac Arrest, Cause Unknown; Patient Refused Further Treatment; Multi System Failure; or Other Identified Cause of Death. In the main classification, theses codes were classified as "Other" except Cardiac Arrest, Cause Unknown that was classified as CVD. To test the impact of this decision on the results, a sensitivity analysis was conducted by excluding patients who had one of these codes. Also, because a large proportion of causes of death were missing in CORR, two sensitivity analyses were conducted where all missing causes were attributed to 1) CVD or 2) other causes.

\section{Ethical considerations}

Permission was obtained to conduct this study by the Government of Québec ethics committee (Commission d'accès à l'information), CORR internal review committee, and Maisonneuve-Rosemont Hospital ethics committee. Informed consent was waived.

\section{Results}

As shown in Figure 1, 5997 patients were identified in the CORR cohort and 6567 patients in the RAMQ cohort. After merging both cohorts, 5858 patients remained in the study cohort. Median age was 68 years (interquartile range: 56 - 75), 39.7\% were female, and the majority was on hemodialysis $(84.2 \%)$ versus peritoneal dialysis (15.8\%) at three months of dialysis initiation. Median follow-up time was 2.0 years $(1.0-3.4)$ using ISQ data.

Among study patients, 1907 deaths were identified using CORR data, while 2074 were identified using ISQ data. In total, $96.4 \%$ of patients had a concordant death status: 3778 were still alive at the end of the study according to both data sources and 1872 had a concordant date of death (same or contiguous month). The remaining patients with non-concordant death status were distributed as follow: 6 were still alive in ISQ but deceased in CORR, 29 had a non-concordant date of death (by a median absolute difference of 120 days), and 173 patients were still alive in CORR but deceased in ISQ. Kappa statistics for concordance between dates of death was excellent: 0.92 (95\% CI: 0.91, 0.93).

\section{All-cause and CVD mortality rates}

All-cause mortality and CVD rates for the dialysis cohort (using CORR or ISQ dates of death) and GP are presented in Figures 2 and 3. Mortality rates were considerably higher in the dialysis population than in the GP. Mortality rate using CORR was lower when using 


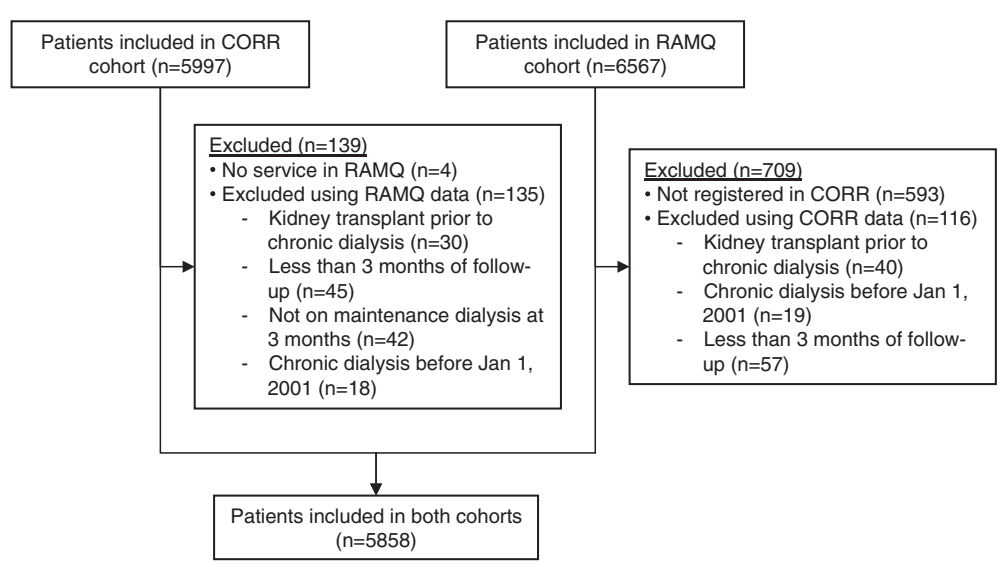

Figure 1 Derivation of dialysis cohorts. Despite meeting all inclusion criteria using RAMQ data, some RAMQ cohort patients were excluded because they were not registered in CORR $(n=593)$ or had been excluded using CORR data $(n=116)$. Similarly, some patients were excluded from CORR because they had no service in RAMQ $(n=4)$ or were excluded based on RAMQ data ( $n=135)$.

ISQ (10.7\%). Differences between CORR and ISQ dates of death also influenced the cumulative survival function, as shown in the Kaplan-Meier curve (Figure 4). CVD mortality rates were lower when using CORR data than using ISQ data, but the gap appeared smaller than with all-cause mortality.

\section{Causes of death distribution and concordance}

Cause of death was missing or unknown in $25.6 \%$ of patients with a reported date of death in CORR, while this proportion was only $1.8 \%$ in ISQ. Distributions of causes for patients receiving dialysis and GP are presented in Table 2. Proportions of death attributed to either CVD or infections were higher using registry data than using underlying cause from death certificates. However, proportions of deaths from infections were similar between registry data and direct cause of death from death certificates. In comparison to the GP, use of death certificate data (underlying cause) resulted in a more conservative discrepancy in CVD deaths between dialysis and GP groups: e.g. in men, the difference in percentage points was reduced from $12 \%(41.5 \%-29.3 \%)$ to $3 \%$ $(32.1 \%-29.3 \%)$, and similarly in women it was reduced from $7 \%(35.2 \%-28.2 \%)$ to $-4 \%(24.3 \%-28.2 \%)$. Differences in percentage points for infections were also reduced to $1.7 \%$ (5.0\%-3.3\%) for men and 1.2\% (4.8\%-3.6\%) for women when using death certificate data (underlying cause).

Using the underlying cause of death, $51.4 \%$ of patients who had a cause of death reported in both CORR and ISQ had congruent death categories (Table 3). Kappa statistic was fair at 0.27 (95\% CI: $0.23,0.31)$. The chi-

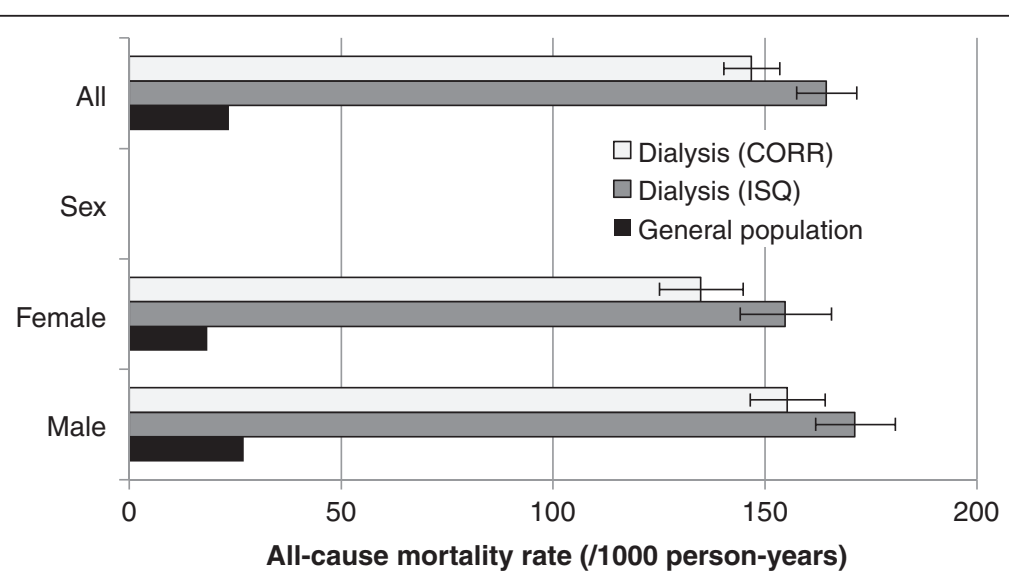

Figure 2 All-cause mortality rates for patients receiving dialysis (using CORR versus ISQ data) and general population. Rates for the general population are age- and sex-adjusted to the study population. Error bars represent $95 \%$ confidence interval of the rates. Abbreviations: $H D$, hemodialysis; PD, peritoneal dialysis. 


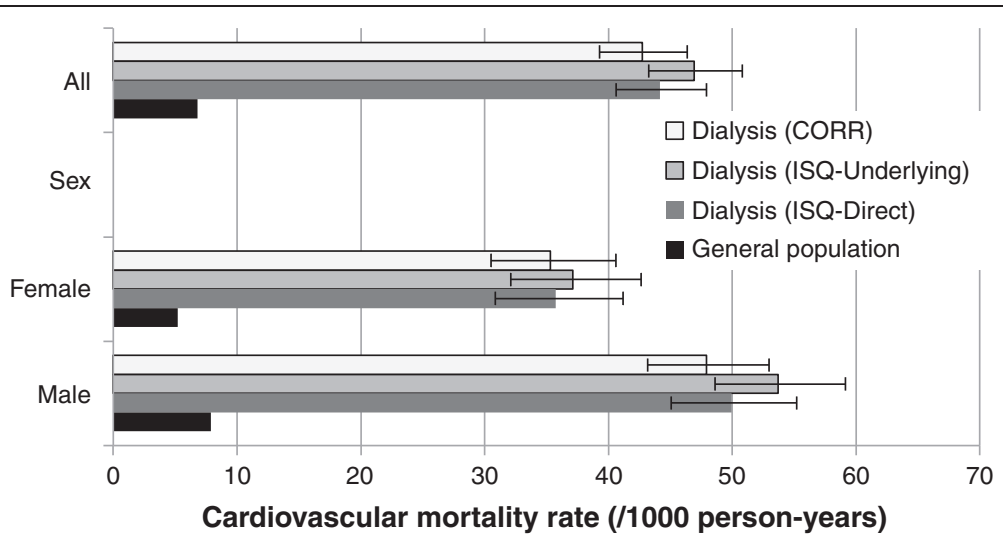

Figure 3 Cardiovascular-related mortality rates for patients receiving dialysis (using CORR versus ISQ data) and general population. Rates for the general population are age- and sex-adjusted to the study population. Error bars represent $95 \%$ confidence interval of the rates.

square test comparing proportions of concordant causes of death between categories was highly significant ( $\mathrm{p}<0.001)$, suggesting that the concordance in causes of death between CORR and ISQ data did not occur by chance. Concordance for causes of death between CORR and ISQ improved when the direct cause of death was used (Table 4). Percent agreement increased to $57.9 \%$ and kappa statistic remained fair at $0.36(0.33,0.40)$.

Among the 173 patients who were considered still alive in CORR but deceased in ISQ, $17.3 \%$ of deaths were attributed to CVD (underlying cause in ISQ database), $2.3 \%$ to infection, $22.0 \%$ to malignancy, $56.6 \%$ to other causes, and $1.7 \%$ were missing.

\section{Sensitivity analyses}

Removing codes possibly overlapping multiple categories (see Methods) did not improve concordance (kappa: 0.31 with underlying and 0.35 with direct cause). Reclassifying missing cause of death in CORR as CVD (kappa: 0.20 with underlying and 0.26 with direct cause) or other causes (kappa: 0.22 with underlying and 0.30 with direct cause) led to slightly worse results.

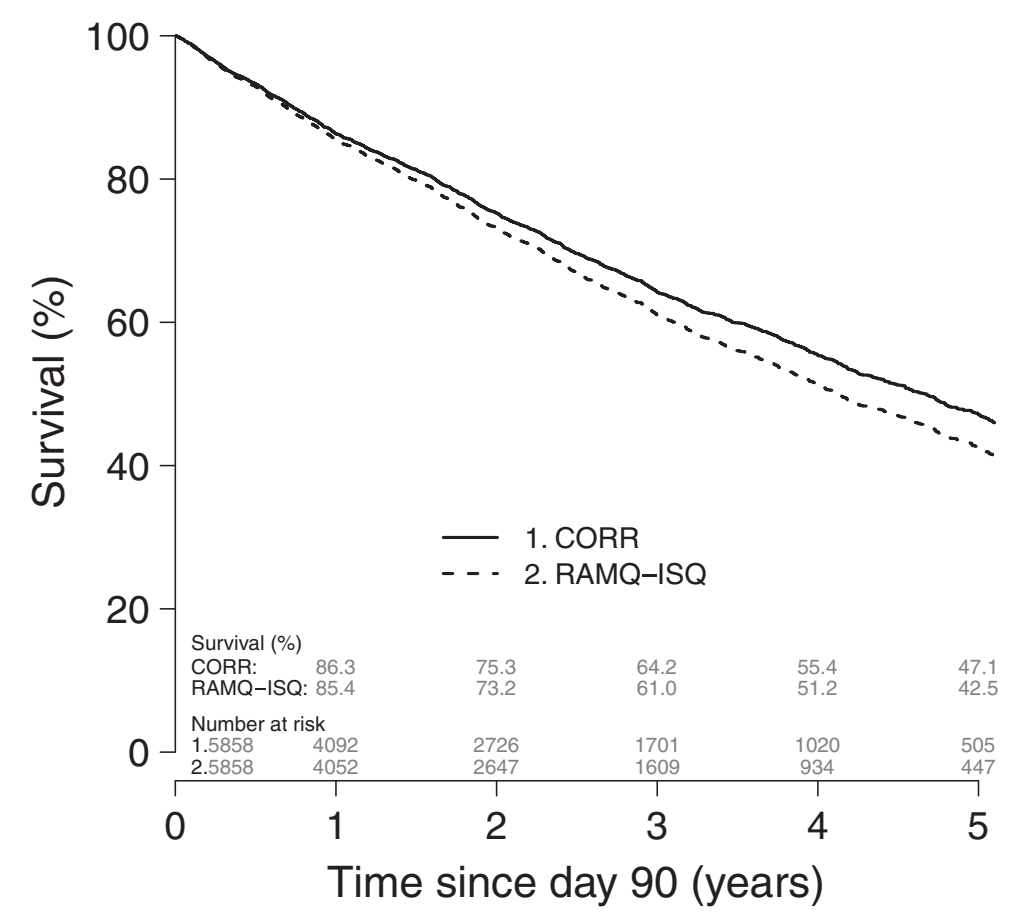

Figure 4 Unadjusted Kaplan-Meier survival curve for all dialysis patients using CORR or ISQ data. Note: Time starts at 90 day after dialysis initiation and the Kaplan-Meier plot was truncated when the number of patients at risk reached 10\% of baseline. 
Table 2 Distribution of causes of death according to CORR and ISQ for patients receiving dialysis and for the general population

\begin{tabular}{|c|c|c|c|c|c|c|c|}
\hline \multirow[t]{2}{*}{ Causes of death } & \multicolumn{2}{|c|}{ CORR } & \multicolumn{2}{|c|}{ ISQ - Underlying cause } & \multicolumn{2}{|c|}{ ISQ - Direct cause } & \multirow{2}{*}{$\begin{array}{c}\text { General population* } \\
\%\end{array}$} \\
\hline & $\mathrm{N}$ & $\%$ & $\mathbf{N}$ & $\%$ & $\mathbf{N}$ & $\%$ & \\
\hline \multicolumn{8}{|l|}{ Both sex } \\
\hline Cardiovascular & 555 & $39.1 \%$ & 592 & $29.1 \%$ & 557 & $27.4 \%$ & $28.9 \%$ \\
\hline Infection & 149 & $10.5 \%$ & 101 & $5.0 \%$ & 222 & $10.9 \%$ & $3.4 \%$ \\
\hline Malignancy & 149 & $10.5 \%$ & 284 & $14.0 \%$ & 153 & $7.5 \%$ & $36.1 \%$ \\
\hline Other & 565 & $39.9 \%$ & 1059 & $52.0 \%$ & 1104 & $54.2 \%$ & $31.6 \%$ \\
\hline Diabetes & N/A & & 339 & $16.7 \%$ & 14 & $0.7 \%$ & $3.3 \%$ \\
\hline Kidney failure & N/A & & 400 & $19.6 \%$ & 576 & $28.3 \%$ & $1.8 \%$ \\
\hline \multicolumn{8}{|l|}{ Female } \\
\hline Cardiovascular & 189 & $35.2 \%$ & 191 & $24.3 \%$ & 184 & $23.4 \%$ & $28.2 \%$ \\
\hline Infection & 62 & $11.6 \%$ & 38 & $4.8 \%$ & 92 & $11.7 \%$ & $3.6 \%$ \\
\hline Malignancy & 59 & $11.0 \%$ & 107 & $13.6 \%$ & 59 & $7.5 \%$ & $34.9 \%$ \\
\hline Other & 227 & $42.3 \%$ & 449 & $57.2 \%$ & 450 & $57.3 \%$ & $33.3 \%$ \\
\hline Diabetes & N/A & & 146 & $18.6 \%$ & 7 & $0.9 \%$ & $3.4 \%$ \\
\hline Kidney failure & N/A & & 161 & $20.5 \%$ & 232 & $29.6 \%$ & $1.6 \%$ \\
\hline \multicolumn{8}{|l|}{ Male } \\
\hline Cardiovascular & 366 & $41.5 \%$ & 401 & $32.1 \%$ & 373 & $29.8 \%$ & $29.3 \%$ \\
\hline Infection & 87 & $9.9 \%$ & 63 & $5.0 \%$ & 130 & $10.4 \%$ & $3.3 \%$ \\
\hline Malignancy & 90 & $10.2 \%$ & 177 & $14.2 \%$ & 94 & $7.5 \%$ & $36.7 \%$ \\
\hline Other & 338 & $38.4 \%$ & 610 & $48.8 \%$ & 654 & $52.3 \%$ & $30.7 \%$ \\
\hline Diabetes & N/A & & 193 & $15.4 \%$ & 7 & $0.6 \%$ & $3.2 \%$ \\
\hline Kidney failure & N/A & & 239 & $19.1 \%$ & 344 & $27.5 \%$ & $1.8 \%$ \\
\hline
\end{tabular}

Note: Cause of death was missing or unknown in 489 patients (25.6\%) in CORR and 38 patients (1.8\%) in ISQ. Kidney failure and diabetes are not defined in CORR internal coding scheme and could not be reported.

*General population of Quebec, Canada, 2001 to 2007, indirectly standardized.

\section{Discussion}

This study reports on the comparison of cause of death proportions between dialysis patients and the GP. It demonstrated poor concordance between registry data and death certificates. This discrepancy between registry data and death certificates led to different conclusions when proportions of death attributed to CVD were compared between the dialysis population and the GP. While
CORR showed a higher CVD death proportion among dialysis patients, ISQ showed almost no difference compared to the GP. While the proportion of deaths due to infection was also higher among dialysis patients using CORR data than when compared to underlying cause of death, proportions estimated from direct cause of death in the death certificate showed that they remained an important complication of disease (biological mechanism)

Table 3 Causes of death for patients with a cause of death in both CORR and ISQ using the underlying cause of death in ISQ

\begin{tabular}{|c|c|c|c|c|c|c|}
\hline & & \multicolumn{4}{|c|}{ ISQ -- Underlying cause } & \\
\hline & & Cardiovascular & Infection & Malignancy & Other & \\
\hline \multirow[t]{5}{*}{ CORR } & Cardiovascular & 237 & 19 & 13 & 274 & $543(39.1 \%)$ \\
\hline & Infection & 24 & 35 & 15 & 74 & $148(10.7 \%)$ \\
\hline & Malignancy & 16 & 1 & 106 & 25 & $148(10.7 \%)$ \\
\hline & Other & 129 & 17 & 67 & 336 & $549(39.6 \%)$ \\
\hline & & $406(29.3 \%)$ & $72(5.2 \%)$ & $201(14.5 \%)$ & 709 (51.1\%) & $1388(100 \%)$ \\
\hline
\end{tabular}


Table 4 Causes of death for patients with a cause of death in both CORR and ISQ using the direct cause of death in ISQ

\begin{tabular}{|c|c|c|c|c|c|c|}
\hline & & \multicolumn{4}{|c|}{ ISQ -- Direct cause } & \\
\hline & & Cardiovascular & Infection & Malignancy & Other & \\
\hline \multirow[t]{5}{*}{ CORR } & Cardiovascular & 286 & 32 & 5 & 220 & $543(39.1 \%)$ \\
\hline & Infection & 14 & 69 & 3 & 62 & $148(10.7 \%)$ \\
\hline & Malignancy & 10 & 12 & 68 & 58 & $148(10.7 \%)$ \\
\hline & Other & 85 & 44 & 39 & 381 & 549 (39.6\%) \\
\hline & & 395 (28.5\%) & 157 (11.3\%) & 115 (8.3\%) & 721 (52.0\%) & $1388(100 \%)$ \\
\hline
\end{tabular}

leading to death. Finally, cause of death was missing in more than a quarter of deaths in CORR, greatly diminishing its usefulness.

Many countries and regions collect and report mortality data from renal dialysis programs using registries. Examples include the United States Renal Data System (USRDS), United Kingdom Renal Registry (UKRR), European Dialysis and Transplant Association/European Renal Association (EDTA/ERA), and Australia and New Zealand Dialysis and Transplant Registry (ANZDATA) [18]. Most dialysis registries use an internal coding system to classify cause of death instead of ICD-10 [2,19]. Reports of distribution of causes of death for patients on dialysis vary between countries, influenced in part by different age distributions and case-mix among populations. CVD remains the most frequent cause in all (31 to $55 \%$ of deaths), followed in most countries by infections (11 to $18 \%$ ), and malignancies (4 to 13\%) [19-21]. Of note, distribution of causes of death reported for the GP are age and sex adjusted to the dialysis cohort. Therefore, causes of death associated with older age have a higher weight, explaining why malignancies are the leading cause of death at $36.1 \%$ in the GP.

Our finding of only fair concordance of cause of death between ISQ and CORR is consistent with results from previous reports using USRDS and ANZDATA (overall kappa from 0.22 to 0.24) [6,7]. One may hypothesize that, in most of those dialysis populations, reported CVD death proportions are likely higher than what would have been reported using DC. To our knowledge, no study has quantitatively evaluated the proportion of deaths attributable to different causes in comparison to GP, using the same source of information (DC) for both populations.

In the UKRR, part of their data (England and Wales) is linked with national vital statistics $[18,22]$. In USRDS, only $1 \%$ of deaths are ascertained through national vital statistics [2]. However, reporting death to USRDS is mandatory. CORR is a voluntary registry with no linkage to vital statistic registries. This may account for some of the discrepancies observed in our analysis. Given that information from registries (such as cause of death) is precious to guide policy, planning and resources we insist that better identification of true causes of death in dialysis populations is important, and that we do have an opportunity to remedy to the current situation in Canada.

While validity of death occurrence and its date is fairly high in vital statistic registries such as ISQ [23], misclassification of the cause of death is known to occur $[7,24,25]$. Of note, neither CORR nor ISQ is a true gold standard for cause of death, which will always be subject to some misclassification. DC, obtained from the ISQ data, constitute the most valid practical tool available to determine the cause of death on a provincial level. This study did not evaluate differences between registry and death certificates coding variation by country. However, as mentioned earlier poor concordance was reported in two other countries, so it is likely that this is a true phenomenon.

\section{Conclusion}

In conclusion, evaluation of causes of death using DC in dialysis patients in Quebec revealed that they do not have substantially different proportion of death due to CVD or infections than the GP. However, infections appeared to be a frequent complication or biological mechanism leading to death. While all-cause and CVD absolute mortality rates remain many times higher among dialysis patients compared to the GP (no matter which source of data), use of registry data alone would lead health care practitioners and researchers to conclude that there is more than 10 percentage points higher proportion of deaths attributed to CVD in dialysis populations than is really the case. In an era of increasing need for accuracy in medical records, we believe that validation of registry data, or development of better linkage with vital statistics in Canada, should be undertaken for dialysis populations. In this way, we may be able to better establish priorities for prevention and therapeutic efforts, or clinical and research resources allocation. While CVD remains an important issue among dialysis patients, infections appear to be an important target to consider as a means to reducing mortality in that population. 


\section{Competing interests}

This work was supported by a Fonds de la recherche en santé du Québec (FRSQ) operating grant. Dr. Lafrance is supported by a KRESCENT New Investigator Award (public funds). The authors have no other competing interests.

\section{Authors' contributions}

JP L (conception and design, analysis and interpretation of data, and writing of manuscript), ER (analysis and interpretation of data, and critical appraisal of article), SI (interpretation of data and critical appraisal of article), ML (interpretation of data and critical appraisal of article), VP (interpretation of data and critical appraisal of article), NE (analysis and interpretation of data and critical appraisal of article), and MV (interpretation of data and critical appraisal of article). All authors read and approved the final manuscript.

\section{Author details}

${ }^{1}$ Centre de recherche Hôpital Maisonneuve-Rosemont, Montréal, Canada. ²Département de Médecine, Université de Montréal, Montréal, Canada. ${ }^{3}$ Service de néphrologie, Hôpital Maisonneuve-Rosemont, 5415, boul. de l'Assomption, Montréal (Québec) H1T 2M4, Canada. ${ }^{4}$ Department of Medicine, McGill University, Montreal, Quebec, Canada. ${ }^{5}$ Research Institute, McGill University Health Centre, Montreal, Quebec, Canada. ${ }^{6}$ Division of Nephrology, McGill University Health Centre, Montréal, Québec, Canada.

Received: 13 September 2012 Accepted: 22 March 2013 Published: 27 March 2013

\section{References}

1. Canadian Institute for Health Information: Treatment of End-Stage Organ Failure in Canada, 2000 to 2009 (2011 Annual Report). Ottawa: ClHI; 2011.

2. U.S. Renal Data System: USRDS 2010 Annual Data Report: Atlas of Chronic Kidney Disease and End-Stage Renal Disease in the United States. Bethesda, MD: National Institutes of Health, National Institute of Diabetes and Digestive and Kidney Diseases; 2010.

3. de Jager DJ, Grootendorst DC, Jager KJ, van Dijk PC, Tomas LM, Ansell D, Collart F, Finne P, Heaf JG, De Meester J, et al: Cardiovascular and noncardiovascular mortality among patients starting dialysis. JAMA 2009, 302(16):1782-1789.

4. Carrero JJ, de Jager DJ, Verduijn M, Ravani P, De Meester J, Heaf JG, Finne P, Hoitsma AJ, Pascual J, Jarraya F, et al: Cardiovascular and noncardiovascular mortality among Men and women starting dialysis. Clin J Am Soc Nephrol 2011, 6(7):1722-1730.

5. Roberts MA, Polkinghorne KR, McDonald SP, lerino FL: Secular trends in cardiovascular mortality rates of patients receiving dialysis compared with the general population. Am J Kidney Dis 2011, 58(1):64-72.

6. Li SQ, Cass A, Cunningham J: Cause of death in patients with end-stage renal disease: assessing concordance of death certificates with registry reports. Aust N Z J Public Health 2003, 27(4):419-424.

7. Perneger TV, Klag MJ, Whelton PK: Cause of death in patients with endstage renal disease: death certificates vs registry reports. Am J Public Health 1993, 83(12):1735-1738.

8. Baigent C, Landray MJ, Reith C, Emberson J, Wheeler DC, Tomson C, Wanner C, Krane V, Cass A, Craig J, et al: The effects of lowering LDL cholesterol with simvastatin plus ezetimibe in patients with chronic kidney disease (Study of Heart and Renal Protection): a randomised placebo-controlled trial. Lancet 2011, 377(9784):2181-2192.

9. Wanner C, Krane V, Marz W, Olschewski M, Mann JF, Ruf G, Ritz E: Atorvastatin in patients with type 2 diabetes mellitus undergoing hemodialysis. N Engl J Med 2005, 353(3):238-248.

10. Wetmore JB, Shireman TI: The ABCs of cardioprotection in dialysis patients: a systematic review. Am J Kidney Dis 2009, 53(3):457-466.

11. Canadian Institute for Health Information: Treatment of End-Stage Organ Failure in Canada, 1999 to 2008 (2010 Annual Report). Ottawa: ClHI; 2010.

12. Fenton SS, Schaubel DE, Desmeules M, Morrison HI, Mao Y, Copleston P, Jeffery JR, Kjellstrand CM: Hemodialysis versus peritoneal dialysis: a comparison of adjusted mortality rates. Am J Kidney Dis 1997, 30(3):334-342.

13. Hemmelgarn BR, Chou S, Wiebe N, Culleton BF, Manns BJ, Klarenbach S, Khan NA, Gourishankar S, Yeates KE, Gill JS, et al: Differences in use of peritoneal dialysis and survival among East Asian, Indo Asian, and white ESRD patients in Canada. Am J Kidney Dis 2006, 48(6):964-971.
14. Jassal SV, Trpeski L, Zhu N, Fenton S, Hemmelgarn B: Changes in survival among elderly patients initiating dialysis from 1990 to 1999. CMAJ 2007, 177(9):1033-1038.

15. Moist LM, Trpeski L, Na Y, Lok CE: Increased hemodialysis catheter use in Canada and associated mortality risk: data from the Canadian Organ Replacement Registry 2001-2004. Clin J Am Soc Nephrol 2008, 3(6):1726-1732.

16. Births and Deaths. http://www.stat.gouv.qc.ca/donstat/societe/demographie/ naisn_deces/index_an.htm.

17. Landis JR, LKoch GG: The measurement of observer agreement for categorical data. Biometrics 1977, 33:159-174.

18. Donovan K, Ford D, van Schalkwyk D, Ansell D: UK Renal Registry 12th Annual Report (December 2009): Chapter 16: International comparisons with the UK RRT programme. Nephron Clin Pract 2010, 115(Suppl 1):c309-319.

19. Australia and New Zealand Dialysis and Transplant Registry: ANZDATA Registry Report 2009. In Edited by McDonald S, Excell L, Livingston B. Adelaide, South Australia; 2009.

20. U.S. Renal Data System: USRDS 2009 Annual Data Report: Atlas of Chronic Kidney Disease and End-Stage Renal Disease in the United States. Bethesda MD: National Institutes of Health, National Institute of Diabetes and Digestive and Kidney Diseases; 2009.

21. Ansell D, Roderick P, Steenkamp R, Tomson CR: UK Renal Registry 12th Annual Report (December 2009): Chapter 7: Survival and causes of death of UK adult patients on renal replacement therapy in 2008: national and centre-specific analyses. Nephron Clin Pract 2010, 115(Suppl 1):c117-144.

22. Ansell D, Tomson CR: UK Renal Registry 11th Annual Report (December 2008): Chapter 15 The UK Renal Registry, UKRR database, validation and methodology. Nephron Clin Pract 2009, 111(Suppl 1):c277-285.

23. Thibault N: Suivi et cycle des naissances et des décès: qu'en est-il au Québec? L'Écostat 2007:11-20. ISSN is 1206-6184.

24. Koepsell T, Weiss N: Epidemiologic Methods: Studying the Occurrence of IIIness. New York: Oxford University Press; 2003.

25. Messite J, Stellman SD: Accuracy of death certificate completion: the need for formalized physician training. JAMA 1996, 275(10):794-796.

doi:10.1186/1471-2288-13-51

Cite this article as: Lafrance et al:: Magnitude of discordance between registry data and death certificate when evaluating leading causes of death in dialysis patients. BMC Medical Research Methodology 2013 13:51.

\section{Submit your next manuscript to BioMed Central and take full advantage of:}

- Convenient online submission

- Thorough peer review

- No space constraints or color figure charges

- Immediate publication on acceptance

- Inclusion in PubMed, CAS, Scopus and Google Scholar

- Research which is freely available for redistribution 